Ponto de Vista

\title{
Conversando sobre psicanálise: entrevista com Judith Butler
}

\author{
Patrícia Porchat Pereira da Silva Knudsen \\ Universidade Paulista
}

\begin{abstract}
A entrevista que se segue teve como ponto de partida minha tese de doutorado em Psicologia Clínica, defendida em 2007, intitulada Gênero, psicanálise e Judith Butler - do transexualismo à política. Logo após a defesa da tese, participei do II Congresso Internacional de Filosofia da Psicanálise, no Brasil, onde conheci a filósofa e psicanalista francesa Monique David-Ménard, do Centre d'Études du Vivant, da Universidade Paris-Diderot. Ela me convidou para assistir a algumas aulas de seu seminário em Paris no ano seguinte, que contariam com a presença de Judith Butler. O tema do seminário do ano 2007-2008 era "Agenciamentos (deleuzianos), dispositivos (foucaultianos) e performativos (butlerianos)". Butler havia proposto a Monique David-Ménard participar como colaboradora das aulas que tratariam sobre o "performativo". A proposta do seminário era pensar de que maneira as noções de agenciamento, dispositivo e performativo ajudam a definir os componentes do espaço da transferência como um espaço que recolhe e transforma a "vida da alma". Foram quatro aulas com a participação de Judith Butler, no mês de junho. A entrevista se deu no dia 24 de junho de 2008, no Café Beaubourg, ao lado do Centro Georges Pompidou, em Paris.
\end{abstract}


Patrícia Porchat: No documentário feito por Paule Zadjermann, Judith Butler, philosophe en tout genre, você diz que o fato de ser lésbica não vem antes de ser mulher, ou judia, ou filósofa. Você diz que não temos apenas uma identidade e que se pode transitar de uma comunidade à outra, em termos de engajamento num movimento, como o movimento gay, por exemplo. Em Undoing Gender você afirma que é uma filósofa feminista. O que é ser feminista hoje e por que ainda é necessário ser feminista hoje?

Judith Butler: Acho que a razão por que digo "sou feminista" em termos enfáticos é que muitas pessoas têm me chamado de pós-feminista ou pensam que faço parte de um movimento pósfeminista. Portanto, estou no processo de refutar essa descrição e talvez historicamente, se não fosse esse o caso, eu pudesse ser mais despreocupada e dizer "Talvez eu seja uma feminista". Mas, dado esse esforço em me situar numa espécie de quadro pós-feminista, eu resisti à linguagem da identidade. Mas certamente há outras ocasiões em que uso a linguagem da identidade - quando sinto que é extremamente importante marcar certo tipo de posição a esse respeito junto a outra pessoa. Depende do contexto do discurso no qual estou operando.

PP: Em que circunstâncias você consideraria importante dizer que é uma feminista?

JB: Bem, eu certamente não acho que estamos vendo o fim da discriminação econômica contra a mulher, não acho que vimos o fim da desigualdade ou da hierarquia de gênero. Não acho que vimos o fim da violência contra a mulher, não acho que vimos o fim de certas concepções profundamente arraigadas sobre quais são as fraquezas das mulheres ou sobre a capacidade das mulheres na esfera pública, ou sobre uma série de outras coisas. Portanto, essas lutas ainda estão muito vivas. Suponho que, para algumas pessoas muito estabelecidas e economicamente seguras, o feminismo já não é tão forte, já não é mais um atrativo, porque elas podem muito bem ser mulheres que hoje ocupam postos de poder e privilégio, ou de segurança econômica, mas isso, com certeza, não é verdade globalmente. Se a gente olha para diferentes níveis de pobreza, diferentes níveis de escolaridade, vê que o sofrimento das mulheres é incomensurável. Então, sim, eu sou uma feminista. Podemos discutir sobre formulações do movimento feminista ou sobre o status de identidade no interior do movimento, e, nesse caso, eu teria discussões com todo tipo de pessoas, mas esse é um debate no interior do movimento, ou pelo menos sobre a direção que o movimento deve adotar.

PP: Eu gostaria de lhe perguntar: as psicanalistas feministas. Entre elas, quais você considera que melhor lidam com a questão dos transgêneros? 
JB: Entre as psicanalistas feministas? Posso pensar num par de pessoas de Nova York, uma delas é um homem chamado Ken Corbett - eu o considero extraordinário - e há uma mulher chamada Adrianne Harris, e, se você procurar na revista Studies in Gender and Sexuality, que é uma publicação de psicanálise e teoria cultural, vai encontrar alguns profissionais que estão pensando nisso de modo interessante. Mas se trata de clínicos, eu sei, que também escrevem ensaios. Acho que os autores mais importantes no campo da psicanálise feminista ainda não fizeram um grande trabalho com isso e não sei se eles estão muito interessados na questão.

PP: Mas existiria uma razão para que dentro das teorias feministas ou do movimento feminista não houvesse interesse na questão dos transgêneros?

JB: Bem, depende. Muitas psicanalistas feministas também estão interessadas em pensar a respeito de raça, ou estão interessadas em pensar em transgênero ou em pensar em crianças, ou seja, ser uma feminista não significa que você só pensa nas mulheres, ou que você adere a uma ideia das mulheres como algo biologicamente fundamentado de alguma maneira. É difícil. Se você está me perguntando sobre a estrutura da teoria, então posso lhe responder de um jeito, mas se você está perguntando sociologicamente, como por que esse grupo particular não expandiria seus horizontes, aí é uma questão diferente. Não tenho certeza de qual das duas você está...

PP: Eu estava pensando num fato que aconteceu no Brasil durante um encontro feminista. Houve uma grande discussão porque parte do movimento aceitava a presença de transgêneros e outra parte não as considerava como mulheres sob nenhuma hipótese. Por isso eu perguntava que teorias feministas levam em conta a possibilidade de ver transgêneros como mulheres. JB: É uma ideia muito boa. O problema é que há alguns psicanalistas que pensam a respeito da transexualidade..., como o famoso livro de Catherine Millot. Mas acho que é um livro horrível, que é uma espécie de patologização. Então, por exemplo, fui conversar com alguns lacanianos outra noite e um deles disse: "Bem, mesmo se pensarmos na transexualidade como uma espécie de psicose, isso não é uma categoria patologizante, pois, quando uma pessoa fala sua psicose, ela está nos dando a estrutura da psique humana, portanto está falando uma verdade universal". Achei aquilo um argumento bastante espantoso, porque, mesmo que o psicótico esteja falando uma verdade universal de algum modo, o fato é que está falando essa verdade a partir de uma posição psicótica e chamá-la de psicótica é invariavelmente patologizante nesse sentido. Isto é, entre os problemas no interior da teoria psicanalítica feminista tradicional, suponho que posso simplesmente lhe dar esta única resposta: as feministas da teoria 
das relações objetais tendem a assumir uma espécie de relação primária, homem e mulher, que traça uma diferenciação de gênero em relação a pessoas que precisam identificar-se ou diferenciar-se da mãe. Assim, se alguém se torna transgênero, isso tende a significar que essa pessoa não segue certo tipo de modelo de desenvolvimento de diferenciação ou identificação de gênero: a identificação na direção da "condição de menina" [girlness] ou a diferenciação na direção da "condição de menino" [boyness]. Portanto, a reprodução de gênero depende da relação diferenciada através do maternal. E há algumas suposições normativas acerca de tornar-se e reproduzir meninas ou tornar-se e reproduzir meninos, e muitas feministas de fato querem que as meninas sejam reproduzidas de maneira a serem capazes de uma autonomia maior e querem que os meninos sejam reproduzidos de maneira a se tornarem menos capazes de violência ou agressão. E esse é o enquadramento feminista, está sempre lá. Mas a questão é como o fato de se tornar uma coisa ou outra passa a ser um problema. Ou a compulsão para se tornar uma menina ou a compulsão para se tornar um menino, isso exerce pressão, e sinto que para compreender isso é preciso ter uma ideia de regulação de gênero que se estenda para além da ideia de desigualdade entre homens e mulheres. Assim, os lacanianos, ou pelo menos as psicanalistas feministas que provêm de uma perspectiva lacaniana...

PP: Você se refere a lrigaray, por exemplo...

JB: ... ou talvez Juliet Mitchell, que agora está mais para kleiniana, com certeza. Juliet Mitchell, no contexto da língua inglesa, estabeleceu uma espécie de parâmetro para a psicanálise e o feminismo com sua obra, e ali a economia estruturalista do dom, você sabe, produz o homem e produz a mulher em certas posições em relação às trocas, e então você tem aquelas posições estruturais. Se a gente vai falar sobre transgênero, terá que ir além desses tipos de posições estruturais, uma vez que simplesmente não é o caso de que toda criatura aparentemente biológica que é fêmea tenha que ser convertida socialmente numa menina ou numa mulher.

PP: Como podemos escapar do pensamento sobre posições estruturais?

JB: O que eu acho mais produtivo são essas feministas que de fato pensam de modo complexo a identificação: as maneiras como as identificações são estabelecidas, ou como o ego corporal é projetado, a maneira como a morfologia é compreendida em relação à fantasia, todas essas coisas me parecem fontes psicanalíticas realmente importantes para pensar o transgênero. E acho que incluiria a melancolia por razões minhas, como creio ter formulado em outro lugar, mas isso me parece muito mais interessante. 
PP: Você está se referindo a algumas psicanalistas em particular? JB: Bem, penso, por exemplo, que há algumas pessoas que provêm das teorias de relações de objeto ou provêm do que é chamado de psicanálise relacional nos EUA, que pensaram muito sobre algumas dessas coisas. Elas estão mais próximas de Jessica Benjamin do que de qualquer outra pessoa de quem falamos, mas também se moveram para fora de seus parâmetros.

PP: No livro de Benjamin podemos perceber uma espécie de essencialismo quando ela diz que os homens "são" de tal maneira e as mulheres "são" de certa maneira. E ela também se refere ao fato de que a mulher, em sociedade, tem o sentimento de que apenas é valorizada quando se torna mãe.

JB: Mas acho que ela mudou. Acho que seu trabalho mais recente é mais aberto. Quero dizer, pelo menos nos EUA, esse grupo tem sido o mais interessante para mim. Estão muito próximos do trabalho de Jéssica Benjamin, mas não exclusivamente. Dianne Ehrenreich, Adrianne Harris, Ken Corbett, Muriel Dimen, estão todos na New York University, no Programa de Pós-Graduação em Psicologia Clínica, e são para mim aqueles com quem me sinto mais à vontade. Devo dizer que a maior parte das pessoas com que converso, que de fato trabalha com pessoas transgênero, é psicóloga clínica, e não psicanalista. Ou é psicóloga clínica com uma base psicanalítica. Mas essas pessoas não passaram pelas escolas, e as escolas são duras, porque eu falo com elas, falo com a Sociedade Psicanalítica de São Francisco, falo com a Sociedade Psicanalítica Internacional em Berlim e encontro a resistência que existe em todas as escolas, as articulações kleinianas, os psicanalistas do ego, os lacanianos, e mesmo do próprio Laplanche, quando falei de fato com ele no ano passado, enfim, a resistência é muito grande.

PP: Você nunca mencionou Joyce McDougall.

JB: Sim, ela é interessante. Gosto do seu trabalho, não o conheço assim tão bem, mas gostei muito do que li. E lamento não ter me envolvido mais com ela, mas talvez ainda o faça. Acho que Françoise Dolto, também, uma parte do seu trabalho em $A$ imagem inconsciente do corpo é ótima para pensar em como o corpo é vivenciado, como sua morfologia é dada ou como é sexuada, como ele se torna ciente ou consciente de si mesmo como um corpo sexual ou como um corpo erógeno. É um trabalho extremamente interessante, esteve em circulação por muito tempo, é parte de uma abordagem psicanalítica mais clássica na França. Há uma tradução para o inglês na revista Differences.

PP: Eu agora gostaria de lhe perguntar um conceito que me parece importante em sua obra. Trata-se do trieb (pulsão), que em inglês aparece como drive. A partir de seu trabalho entendo que até a própria pulsão poderia ser compreendida como 
socialmente construída. Mas também entendo que, em Undoing Gender, você diz que a pulsão é condição para uma transformação social. Então, quando você fala de pulsão, está se referindo à pulsão freudiana, à pulsão lacaniana, à pulsão deleuziana?

JB: Tudo o que sei é o seguinte: não tenho uma formulação explícita do tipo "Esta é a minha teoria da pulsão". Mas posso dizer algumas coisas a respeito. $O$ ensaio de Freud $A$ pulsão e suas vicissitudes (Trieb und ihre Schicksale) foi muito importante para mim desde que eu tinha 22 anos. E penso que ali ele introduz a ideia da pulsão como conceito-limite, existindo no limiar entre corpo e ideia ("soma" e ideia). E julgo isso extremamente interessante. A pulsão nunca é plenamente capturada pelas ideias, nem tampouco é plenamente redutível a um corpo biológico, mas existe no ponto de sobreposição entre eles, e Freud chega a dizer que a pulsão é parte dessa linguagem figurativa, é parte da poesia dele. Eu me interesso pelo que Deleuze faz com as pulsões em Vênus das peles e em seus primeiros trabalhos sobre Sacher-Masoch. Acho extremamente interessante. A ideia de pulsion, em francês, é provavelmente um pouco diferente, mas ali penso em pulsões como estando a serviço de um perpétuo deslocamento. Mas acho que talvez a pessoa mais importante para mim no tocante a pulsões seja Laplanche e a discussão contida em Vida e morte na Psicanálise. Acho que ele tem uma tese brilhante, que é a de que não há nenhuma teleologia natural para uma pulsão e de que as pessoas que entendem pulsão como um impulso para a reprodução sexual cometem um erro. Ele diz que as pulsões sexuais não têm nenhum telos inerente, nenhum fim ou meta necessários. Assim como você não pode dizer que uma pulsão sirva à função social de reprodução, porque uma pulsão está sempre se desviando do objetivo social para o qual é direcionada. Portanto, não se pode regular efetivamente as pulsões, porque elas sempre vão escapar, ou adotar outro objeto que não o previsto. E para mim isso é ótimo, porque Laplanche realmente defende o argumento de que a sexualidade não está vinculada à reprodução da espécie, e isso é crucial, quero dizer, ela pode ser vinculada, ela pode ser levada a seguir nessa direção, mas isso não é inerente à sexualidade em si. Portanto, tomo isso como um ponto importante.

PP: Tenho a impressão de que, quando você escreve e pensa, você sempre tem uma interlocução com a psicanálise. Ela está sempre lá. Mas, ao mesmo tempo, não é algo.

JB: ... em que eu mergulhe. Pensei nisso talvez uns dez anos atrás, mas não acho que eu seria muito boa nisso. Para mim é uma teoria muito importante, uma prática muito importante. Estou envolvida com suas tradições, com sua teoria, quanto a isso não há dúvida. Mas sinto também que ela precisa ser posta em 
contato coma a Teoria Cultural e a Política Cultural, de um modo mais geral. Então eu me vejo arranjando um encontro ou alguma espécie de reunião entre psicanálise e movimentos sociais mais amplos, políticas culturais e questões relativas a gays, lésbicas, $\mathrm{bi}$, trans, intersexo. Preocupa-me o fato de que tantas pessoas nesses movimentos resistam à psicanálise, que julguem que a psicanálise não é mais do que regulação social, normalização. E por outro lado os psicanalistas resistem de verdade a isso, acham que estão trabalhando numa esfera completamente separável da psique, que esta é autônoma, que segue suas próprias regras, como se o que acontece no interior da transferência fosse algo isolado do que ocorre no mundo exterior. Acho que esse não é um antagonismo necessário, porque a psicanálise pode fornecer uma crítica vigorosa da normalização, uma crítica vigorosa da regulação social, pode nos proporcionar uma teoria da fantasia, pode colocar em questão o corpo natural, pode observar o modo como o poder social toma forma na psique, há várias maneiras de se fazer isso. E acho que os movimentos sociais preocupados com isso podem entender melhor sua própria situação a partir de uma perspectiva psicanalítica $\mathrm{E}$ talvez até desenvolver vocabulários mais complexos para pensar a identidade, ou o desejo, ou a solidariedade, três conceitos essenciais para esses movimentos. Mas não quero estar "dentro" de nada, acho que não é meu papel, não é meu trabalho.

PP: Considerando a ideia de ser humano, você acha possível que, a partir da psicanálise, seja possível conceber alguma ideia universal de ser humano?

JB: Antes de tudo, não sei se existe algo universalmente verdadeiro sobre todos os humanos. Eu me preocupo com as normas que governam a questão de quem será considerado humano e quem não, mas não acho que exista um humano fora das normas. Penso que algo acontece quando as normas se rompem, ou quando se resiste às normas, ou quando as normas produzem um campo de assim chamados seres humanos fora das normas. E isso é interessante para mim porque há um modo pelo qual a categoria do humano ao mesmo tempo permite o reconhecimento de certos humanos e produz uma impossibilidade para outros. E a esses outros nós chamamos de humanos? De que os chamamos? É uma questão em aberto. Então penso que o humano sempre produz o espectro da mente e é para isso que estou olhando. Não acho que exista uma forma humana singular, não acho que exista uma capacidade humana singular, mas o que eu acho sim, provavelmente na base do meu trabalho há essa suposição, é que os seres humanos, se as condições sociais forem solidárias - e esse é um requisito importante -, se as condições sociais forem solidárias, os seres humanos, como os outros animais, buscam 
persistir em seu próprio ser. Essa é uma formulação de Spinoza, na Ética. E isso é interessante na medida em que em Spinoza e em Deleuze o indivíduo persiste em seu próprio ser apenas em relação aos outros, e apenas na medida em que as relações com os outros permitem uma grande afetividade ou uma maior expressividade desse desejo de viver. E é por isso que as condições sociais precisam ser propiciadoras. Não é uma capacidade interna, é uma capacidade que vem a ser vivida e exercida nas relações sociais. Então para mim não é uma parte monádica da minha existência, é algo que só se torna possível no contexto de um conjunto de relações. Não posso persistir em meu próprio ser sem ser parte de um mundo social que torna isso possível e em relação com outros, que, em certo sentido, precisam solicitar ou apoiar meu desejo de viver.

PP: Então você tem que ser reconhecido por esse outro.

JB: Sim, o reconhecimento é uma faca de dois gumes, ele pode facilitar o desejo e pode também matar o desejo. É um risco.

PP: Quando você fala de reconhecimento, qual é a diferença que se pode estabelecer em relação à ideia de inteligibilidade que aparece em Problemas de gênero?

JB: Quando falamos sobre o campo da inteligibilidade de gênero, estávamos falando sobre instituições, categorias e linguagens existentes que podem fazer com que o gênero tenha sentido. O reconhecimento é uma relação intersubjetiva, e, para um indivíduo reconhecer o outro, ele tem que recorrer a campos existentes de inteligibilidade. Mas o reconhecimento também pode ser o lugar onde os campos existentes de inteligibilidade são transformados. Assim, se perguntarmos como nos deslocamos de um campo de inteligibilidade a outro, quero dizer que é possível pedir para ser reconhecido de uma maneira que, pelo menos inicialmente, é ininteligível: as pessoas dizem que não posso fazer isso, "não sei o que você está dizendo, não faz sentido, eu recuso". Mas é marcar posição no campo da inteligibilidade, revisá-lo e expandi-lo, de modo que uma nova forma de reconhecimento seja possível. Ou o indivíduo pode dizer: "não quero ser reconhecido por meio de nenhum dos termos que você tem", e nesse ponto aquele campo de inteligibilidade é recusado e uma distância crítica se estabelece. Invocamos campos de inteligibilidade quando reconhecemos outros, mas também podemos retrabalhá-los ou resistir a eles no curso de novas práticas de reconhecimento.

PP: Quando você falou sobre gênero como ato performativo, você disse que era um ato intencional e performativo. Na transferência, durante um tratamento psicanalítico, algo pode mudar porque existe uma repetição e essa permite mudanças. Essa ideia de uma repetição que permite mudanças está presen- 
te em Problemas de gênero. Entendo que você quer dizer que não é apenas na situação de análise que uma mudança é possível. Na repetição, fora da situação de análise, algo falha e a transformação pode acontecer.

JB: Entendo o que você diz, mas me diga como isso se relaciona com a questão do intencional e do performativo.

PP: Quando repetimos um ato, o que significa dizer que há intencionalidade? Intencional pode ser entendido como uma espécie de voluntarismo, mas quando esse ato fracassa, quando o ato performativo fracassa, você dirá que há algo que escapa. Se transportarmos isso para a ideia de que nos fazemos homens ou mulheres na repetição de atos, mas que algo pode falhar ou fracassar nessa repetição, essa falha ou fracasso não é intencional. JB: Aí é que está o problema, há dois sentidos de intencional, um deles que significa deliberado, voluntário, uma escolha, mas o outro vem da fenomenologia, e aí ele, de fato, significa que, se eu digo algo, a estrutura do meu discurso é intencional, significa que ele se refere a alguma coisa no mundo.

PP: Essa é a ideia fenomenológica de que a consciência é intencional, sempre visa a um objeto, está sempre em relação com alguma coisa.

JB: Isso. Se pensarmos na performatividade nesse sentido fenomenológico, eu pratico um gênero, mas não o pratico num mundo solipsista, estou sempre, em certo sentido, me referindo a, comentando, habitando, retrabalhando um conjunto de normas de gênero que estão em mim e também fora de mim, então isso é intencional no sentido de que está se referindo a um mundo exterior. Mas não quero dizer que o gênero seja totalmente consciente ou que seja totalmente voluntário, pois acho que não é.

PP: Quando você colocou as coisas nesses termos?

JB: Usei essa formulação uma vez, num artigo antigo, talvez 20 anos atrás, mas apenas querendo dizer isso naquele sentido fenomenológico limitado, mas penso que ele implicava um comprometimento excessivo com uma ideia de consciência da qual eu provavelmente abriria mão hoje em dia.

PP: Isso aparece em Problemas de gênero.

JB: Eu uso essa ideia em Problemas de gênero?

PP: Sim, mas você não faz referências à fenomenologia. É por isso que o termo "intencional" parece se referir a voluntarismo. JB: Bem, essa é uma maneira de ler Problemas de gênero que vem causando alguns problemas, mas de fato não me lembro de ter dito isso em Problemas de gênero, achei que tinha dito antes. Mas se você diz que está lá eu acredito, ou eu me coloco numa situação complicada. 
PP: Para terminar, no que você está trabalhando agora?

JB: Bem, estou trabalhando em alguns manuscritos, um dos quais na verdade é sobre a guerra. Estou pensando numa espécie de continuação de Precarious Life e tenho uma série de ensaios sobre tortura e política sexual. O outro é um debate sobre secularismo e política sexual, outro sobre vulnerabilidade e capacidade de sobrevivência, pensando no modo como as populações são consideradas distintamente precárias ou não, e talvez pensando um pouco mais acerca da corporificação (embodiment) como uma situação de precariedade. Outro é sobre filosofia e crítica judaica da violência de estado, porque faço parte de uma "esquerda judaica" que é crítica de Israel.

PP: Sua reflexão sobre vulnerabilidade tem algo a ver com as ideias de Giorgio Agamben acerca da "vida nua"?

JB: Acho que discordo dele na questão da "vida nua" porque, para mim, quando estamos falando sobre populações despossuídas ou refugiadas, ou sem direitos, ou de fato contidas em estruturas coloniais como Gaza, ou encarceradas em Guantanamo, não estamos falando daqueles que foram lançados para fora da política, que foram expostos, de uma maneira nua, à força bruta. Estamos, na verdade, falando sobre situações nas quais o poder se sedimentou tão completamente nas vidas dessas pessoas que não há nenhum meio de escapar do poder. Então eu acho que ele usa uma ideia muito idealista de política e, portanto, penso que "vida nua" é fora do político. Acho que aquilo de que ele está falando em Poder soberano e Vida nua é, em si, uma situação altamente política, uma situação que opera talvez fora da lei, certamente não fora do poder. Discordo dele em sua leitura de Kant e de Foucault, mas acho que estamos ambos preocupados com o mesmo tipo de fenômeno. Há uma sobreposição de preocupações ali.

Paris, junho de 2008. 